\title{
NOVAS PERSPECTIVAS DE DESENVOLVIMENTO: UMA ANÁLISE DA ENERGIA EÓLICA NO BRASIL
}

\author{
Calisto Rocha de Oliveira Neto* \\ Elaine Carvalho de Lima**
}

\begin{abstract}
Resumo
Este artigo objetiva analisar a consolidação da atividade eólica no Brasil e sua perspectiva ao desenvolvimento regional. Em termos metodológicos, a pesquisa desenvolveu-se através de uma revisão bibliográfica e documental, bem como da análise descritiva de dados coletados em instituições públicas e privadas relacionadas ao setor. Os resultados mostraram que os programas de incentivo ao crescimento da energia eólica alavancaram os investimentos, proporcionando maior conhecimento e competitividade. Esse panorama beneficia aspectos do desenvolvimento regional, social e ambiental, além de diversificar a matriz energética nacional. Assim, com o Estado promovendo políticas de incentivo, há uma atração de investimentos nacionais e estrangeiros no país, que expande a produção e, consequentemente, fomenta a formação de um polo industrial, principalmente na região Nordeste, devido ao seu maior potencial em recurso eólico.
\end{abstract}

Palavras-chave: Desenvolvimento regional. Energia eólica. Nordeste.

\footnotetext{
* Mestre em Economia pela Universidade Federal do Rio Grande do Norte (UFRN). Graduado em Ciências Econômicas na mesma instituição.E-mail: calisto_neto@hotmail.com.

** Doutoranda em Economia pela Universidade Federal de Uberlândia (UFU). Mestre em Economia pela Universidade Federal do Rio Grande do Norte (UFRN). E-mail: elainecarvalhoonline@hotmail.com.
} 


\section{Introdução}

A história do homem está diretamente ligada ao desenvolvimento da energia, que se transformou em um elemento essencial para suas atividades e para o alcance do desenvolvimento socioeconômico. Sendo assim, a humanidade criou uma crescente necessidade por energia, que tem causado uma dependência energética cada vez maior para garantir a produção de bens de serviços e o bem estar doméstico e social (GOLDEMBERG, 2010).

Nesses termos, o homem vem desenvolvendo e dominando tecnologias ao longo da sua história, que permitiram controlar diferentes estágios do conhecimento científico; deles, destaca-se o desenvolvimento do setor energético, um dos mais bem sucedidos setores da economia capitalista. Diversas fontes de energia foram utilizadas durante a evolução da humanidade, principalmente os combustíveis fósseis, como, petróleo, carvão, nuclear e gás (OLIVEIRA NETO, 2016). Tais fontes se tornaram essenciais para suprir a crescente demanda energética mundial. Entretanto, com o atual debate sobre a questão da preservação ambiental, essas fontes têm se mostrado cada vez mais insustentáveis - do ponto de vista econômico, por se tratarem de recursos finitos, e, do ponto de vista ambiental, por causa dos seus impactos negativos para a natureza (SACHS, 2007).

Diante desse cenário, é necessário o desenvolvimento de novas soluções tecnológicas, que possibilitem viabilizar a utilização de outras fontes menos agressiva ao meio ambiente, pois, de acordo com a International Energy Agency (IEA, 2015), o consumo de energia elétrica a partir de combustíveis fósseis continuará em alta nos próximos anos. Por isso, é necessário buscar alternativas em que a dicotomia entre assegurar o suprimento de energia e amenizar os impactos ambientais seja solucionada. Nesse sentido, há uma preocupação, no mundo, em desenvolver fontes renováveis de energias, de forma a se ter fontes mais viáveis e com menor impacto ao meio ambiente no cenário global de produção de energia. 
Nesse contexto, os investimentos em energia eólica vêm consolidando esta fonte como uma das mais promissoras fontes de geração de energia em grande escala. Em termos percentuais, a energia eólica é a grande responsável pelo crescimento na geração de energia por fontes renováveis no mundo. A energia eólica responde por 34\%, seguida por hidroelétricas com 30\% e por usinas heliotérmicas com 18\% (IEA, 2015). Por depender da abundância de ventos, a produção faz-se presente apenas em determinados espaços, de modo que o seu pleno desenvolvimento pode impactar positivamente a estrutura produtiva dos mesmos, viabilizando um desenvolvimento local ou regional.

Dessa maneira, torna-se importante à análise da atividade eólica a partir de uma abordagem desenvolvimentista, como uma tentativa de compreensão de como o processo de transformação espacial pela energia eólica pode se enquadrar nas dimensões do desenvolvimento brasileiro. Furtado (2000) afirma que a ideia de desenvolvimento abarca um processo de transformação ligada a métodos mais efetivos, proporcionando aumentos do fluxo de bens e de serviços voltado para a sociedade. Assim, as preocupações com o espaço e com sua gestão buscam entender as diferenciações espaciais, desenvolvendo políticas para atenuar as desigualdades locais e regionais.

Nessesentido,o presente trabalhobuscaanalisara atividade eólica no Brasil como oportunidade para o desenvolvimento regional e para a complementação da matriz elétrica nacional. Em termos metodológicos, a pesquisa desenvolveu-se através de uma revisão bibliográfica e documental, bem como da análise descritiva de dados coletados em instituições públicas e privadas relacionadas ao setor.

Este artigo está dividido em cinco seções, a começar pela introdução. A segunda seção trata do referencial teórico sobre a questão regional. $\mathrm{Na}$ terceira seção, analisa-se a possibilidade de inserção da energia eólica na matriz elétrica nacional. Na quarta seção, é feita uma análise dos desafios e das oportunidades para o desenvolvimento do setor eólico 
no Nordeste. Por fim, a quinta seção encerra o artigo com as considerações finais.

\section{Abordagem desenvolvimentista e a questão regional}

O estudo da localização das atividades no espaço não é algo recente, uma vez que perpassa os problemas decorrentes das vantagens geográficas de cada local, do arcabouço econômico e institucional, do acesso aos fatores de produção, entre outros aspectos. Entretanto, ao investigar a história econômica, observa-se a existência de poucos autores que destinaram seus estudos ao espaço (LIMA, 2015). Como enfatizado por Benko (1999, p. 28), “Curiosamente, e apesar de os homens terem vivido no espaço, os economistas ignoraram durante muito tempo esta evidência".

As teorias clássicas de localização se respaldaram no questionamento sobre qual é a melhor área para o desenvolvimento de determinada atividade, relacionando-a com a maximização dos lucros e com a minimização dos custos (CLEMENTE, 1994; LIMA, 2015). Para Ottaviano e Thisse (2004), tais teorias podem ser concebidas como resultante de forças aglomerativas e desaglomerativas, ou seja, a concentração e a desconcentração das atividades produtivas em uma área geográfica ocorreria a partir das vantagens oferecidas pela região. Assim, "o fator locacional constitui um ganho, uma redução de custos, que uma atividade econômica obtém, quando se localiza em um dado ponto. Certamente, seus custos totais seriam mais altos em outros locais" (HADDAD; ANDRADE, 1989, p. 78).

A partir da década de 1950, a complexa problemática das desigualdades regionais brasileiras passou a ter relevância no debate econômico. Para essa abordagem, o fator espacial passou a ser a variável fundamental para explicar as causas e as razões das dinâmicas da economia (SOUZA, 1981; BENKO, 1999). No Brasil, diversos estudos e correntes de pensamento foram produzidos para tentar explicar as disparidades econômicas entre regiões. Nesse sentido, 
destacam-se os estudos realizados pela Comissão Econômica para a América Latina (CEPAL), criada em 1948. Sua criação foi inspirada pelo espírito desenvolvimentista do pós-guerra e delineou um intenso debate, de forma ampla e democrática, sobre as questões relativas à política econômica e social dos países latino-americanos, na tentativa de contribuir para o desenvolvimento da região. Surgiria, assim, uma escola de pensamento econômico próprio e de relativa autonomia para estudar os problemas de subdesenvolvimento dos países da América Latina, formando um caráter crítico e, de certa maneira, inovadora em termos de teoria e de prática de economia (FURTADO, 1966).

Nesse sentido, para Furtado (2000, p. 22), o desenvolvimento engloba, pelo menos, três dimensões:

[...] a do incremento da eficácia do sistema social de produção, a da satisfação de necessidades elementares da população e a da consecução de objetivos a que almejam grupos dominantes de uma sociedade e que competem na utilização de recursos escassos. A terceira dimensão é, certamente, a mais ambígua, pois aquilo a que aspira um grupo social pode parecer para outros simples desperdício de recursos. Daí que essa terceira dimensão somente chegue a ser percebida como tal se incluída num discurso ideológico.

Para Furtado (1992), a estrutura dessas dimensões dá sustentação ao desenvolvimento econômico e social. Segundo o autor, a estrutura social está diretamente ligada ao seu estágio de desenvolvimento, de modo que a formulação de uma política de desenvolvimento e sua implantação não estão alheias a uma estrutura ideológica. Por fim, Furtado aborda as teorias de desenvolvimento como "esquemas explicativos dos processos sociais em que a assimilação de novas técnicas e o conseqüente aumento de produtividade conduz à melhoria do bem estar de uma população com crescente homogeneização social" (FURTADO, 1992, p. 39).

Historicamente, o processo de formação do espaço econômico do Brasil só pode ser entendido a partir de uma 
perspectiva da forma de integração do mercado interno e da política econômica praticada ao longo dos anos. Isso posto, o Estado, através de suas políticas (sejam elas cambiais, tributárias ou de crédito), assim como da dotação de infraestrutura e de incentivos, traçou o desenvolvimento regional recente do país (PACHECO, 1997; OLIVEIRA, 2012).

O processo de desenvolvimento industrial, no Brasil, teve sua origem na região Sudeste, especialmente em São Paulo. A dinâmica gerada pelo processo de concentração regional em São Paulo provocou vários efeitos nas regiões periféricas, como destruição, estímulo e inibição, o que, em parte, resulta em uma restrição de autonomia que aquele estado imprime às regiões subdesenvolvidas através das relações capitalistas desiguais de produção. Assim, as crescentes desigualdades regionais decorrentes, no período que compreende os anos de 1930 a 1970, com taxas diferenciadas de crescimento e de renda entre o centro dinâmico da economia nacional, localizada na região Sudeste, e as regiões periféricas, dá-se pela lógica capitalista de localização industrial (CANO, 2008).

Como forma de atenuar essas disparidades regionais, foi criado o Grupo de Trabalho para o Desenvolvimento do Nordeste (GTDN) na década de 1950. O Estado interveio na economia com o objetivo de incentivar a industrialização de regiões periféricas, bem como desconcentrar o setor industrial e direcioná-la para espaços econômicos incipientes.

Em 1959, o governo criou a Superintendência do Desenvolvimento do Nordeste (SUDENE), uma instituição específica para tratar e promover o desenvolvimento da região Nordeste. A SUDENE tinha o objetivo de promover o desenvolvimento econômico através do processo de fomento à industrialização do território nordestino, que,consequentemente, criaria um polo dinâmico centrado em atividades industriais modernas. Para isso, o Estado usou a estratégia de estímulos governamentais, através de incentivos fiscais e de investimentos estatais diretos em setores com base industrial.

A partir da década de 1970, houve desconcentração das atividades em resposta às políticas estatais. Esse período é 
marcado por crescimento econômico em todas as regiões. Foi um dos períodos de maior crescimento econômico para o país, o que ficou conhecido na literatura como "milagre econômico". Além do crescimento, houve desconcentração industrial, provocada pelas políticas econômicas territoriais viabilizadas pelo Estado a partir de grandes projetos econômicos levados para outras regiões do país, além da Sudeste (CANO, 2008; PACHECO, 1997).

A década 1980, porém, foi caracterizada como a "década perdida" devido à crise da dívida externa brasileira. Nela, houve dois momentos importantes: o primeiro ocorreu até a metade da década de 1980, na qual a maturação de investimentos realizados na década anterior impactou positivamente o crescimento econômico, sobretudo nas regiões subdesenvolvidas; o segundo ocorreu na segunda metade da década, caracterizando-se pelo baixo desempenho econômico regional e nacional.

Os anos 1990 tiveram reformas econômicas importantes na economia brasileira. Nesse período, a economia continuou com baixo crescimento econômico, principalmente no começo da década, quando foram introduzidas mudanças estruturais no país. O período é caracterizado pela saída do Estado desenvolvimentista e indutor do planejamento e crescimento econômico (CANO, 2008). São adotadas, então, políticas neoliberais caracterizadas pela valorização cambial, pelo abandono do projeto nacional desenvolvimentista, pelas privatizações e pela extinção da política de desenvolvimento regional e de instituições regionais de fomento ao desenvolvimento. Além do impacto provocado por essas políticas, o parque industrial brasileiro foi fortemente atingido pela valorização da moeda, solução adotada para segurar a inflação, que vinha desestabilizando a economia desde a década passada.

Assim, diante de uma conjuntura histórica e de um processo de desenvolvimento desigual entre regiões, as reformas neoliberais dos anos 1990 provocaram, entre os estados subdesenvolvidos da nação, uma guerra fiscal, 
passando a ser predominante a política de fomento de atração de investimentos produtivos em todo o território nacional.

Logo, a economia brasileira passou por várias fases e cenários de desenvolvimento e de crescimento econômico, ao longo das últimas décadas, em que ocorreram significativas mudanças estruturais no país. Todavia, as desigualdades ainda persistentes no país suscitam políticas econômicas que possam atenuar esse obstáculo. Oliveira (2012) ressalta que a política econômica deve harmonizar o equilíbrio das contas externas, garantindo a estabilidade monetária e a promoção do crescimento econômico de maneira sustentável, com uma melhor distribuição de renda.

Em suma, as desigualdades econômicas entre regiões e suas atividades no espaço são o objeto de estudo da economia regional. Sendo assim, os diferentes níveis de desenvolvimento econômico suscitam a necessidade de políticas públicas voltadas para o atendimento às particularidades de cada região. Logo, o desenvolvimento de novas atividades, em certos espaços, pode determinar a criação de certas situações de sucesso econômico na região, possibilitando que esses espaços tenham polos industriais de desenvolvimento, como é o caso do complexo produtivo da energia eólica, que pode tanto atender parte da demanda por energia elétrica quanto possibilitar a industrialização do setor no Nordeste, já que esta região possui maior potencial explorável do Brasil.

\section{Inserção da energia eólica na matriz elétrica nacional e seus impactos no desenvolvimento regional}

Historicamente, a formação da matriz elétrica brasileira foi pensada estrategicamente, a partir dos anos 1930 (quando inicia a industrialização de sua economia), com a utilização de fonte hidrológica para garantir o crescimento e o desenvolvimento econômico brasileiro. Atualmente, segundo dados da Associação Brasileira de Energia Eólica (ABEEólica, 2015), as usinas hidrelétricas correspondem a 61,3\% do total da capacidade instalada da matriz elétrica e a mais de $80 \%$ quando 
somada a outras fontes renováveis. Para Castro et al. (2010), a matriz elétrica brasileira apresenta uma composição singular e privilegiada quando comparada às matrizes de outros países. É um perfil que dá ao Brasil vantagens comparativas, pois é uma estrutura que garante a oferta de eletricidade a preços competitivos. No entanto, é importante destacar que a geração de eletricidade por hidrelétricas dependente do regime de chuvas, uma vez que não há garantia de precipitação regular todos os anos; assim, quase todo o Sistema Elétrico Brasileiro (SEB) é caracterizado por um comportamento sazonal.

As hidrelétricas foram construídas aproveitando a exploração de economias de escala, ou seja, quanto maior a produção de energia elétrica por unidade produtiva, menor serão os custos médios. Logo, o valor da tarifa pode ser bastante competitiva. Desse modo, a característica de ter grandes reservatórios é explicada por dois motivos, basicamente: primeiro, foi feito assim em razão da própria urgência em industrializar a economia brasileira, de modo que, era necessário preços mais competitivos; Segundo, porque era preciso atender os grandes centros urbanos, principalmente os das regiões Sul e Sudeste do Brasil (OLIVEIRA NETO, 2016). Assim, a demanda por energia acompanhava a expansão da economia, o que exigia a exploração de hidrelétricas em outras regiões do país, principalmente na região Norte (amazônica), pois o potencial hídrico remanescente está nesta regi (CASTRO et al, 2010).

Todavia, a construção de novas hidrelétricas na região da Amazônia tem encontrado embates, crescentemente, e questionamentos quanto aos seus impactos sociais remanejamento de comunidades tradicionais indígenas e das populações de entorno, perda dos laços culturais e comunitários, inundação do patrimônio tangível e de locais sagrados, surgimento de doenças, insegurança e incerteza, dentre outros - e ambientais - alagamento de áreas florestais, desaparecimento do habitat da fauna e da flora existente, extinção de espécies, perda da biodiversidade, tremores de terra, dentre outros (OLIVEIRA NETO, 2016). 
Diante desse cenário de mudança estrutural na matriz elétrica brasileira, são fundamentais pesquisas e estudos sobre o potencial e a viabilidade econômica e ambiental para introduzir e ampliar a participação das fontes alternativas na matriz. Então, avalia-se que, o grande potencial em recurso eólico, no Brasil, apresenta-se como importante vantagem ao SEB, pois complementa a produção de energia das hidrelétricas e sua operação gera menos impactos ambientais. Ademais, a instalação de turbinas eólicas pode operar também no período seco do ano, durante o qual os reservatórios das hidrelétricas estão baixos. Estudos feitos nos períodos de seca mostram que, justamente os meses em que chove menos são os que apresentam ventos mais fortes e intensos, sobretudo na região Nordeste do país, conforme Figura 1 a seguir:

Figura 1 - Vazão do Rio São Francisco e Comportamento dos Ventos na Região Nordeste

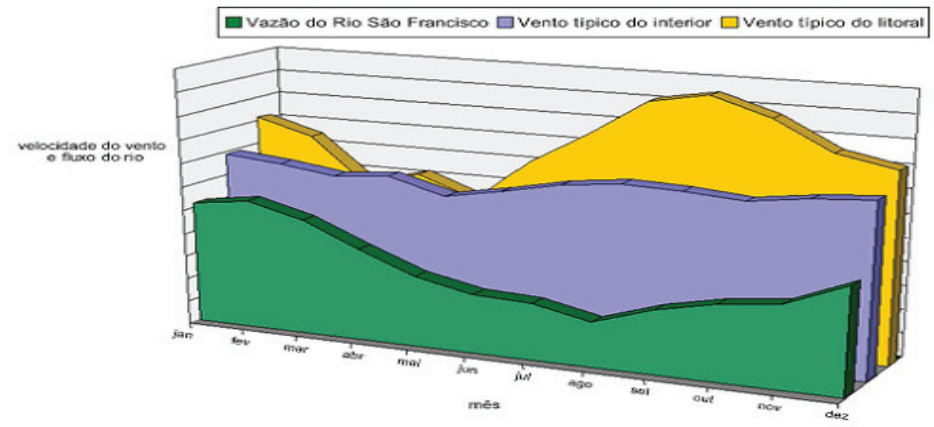

Fonte: Dutra, 2001

Do lado da oferta de energia eólica, o território brasileiro apresenta enorme viabilidade técnica. Estudos realizados em 2001 estimaram que o país tem mais de 143 gigawatts (GW) de capacidade com torres de 50 metros. Com torres eólicas de 100 metros, o potencial pode ultrapassar os 300 GW. Em termos regionais, o Nordeste apresenta o maior potencial para produzir energia elétrica por aerogeradores: são mais de $75 \mathrm{GW}$ do total nacional, como se pode ver na Figura 2 (CRESESB, 2001): 
Figura 2 - Potencial eólico na região Nordeste

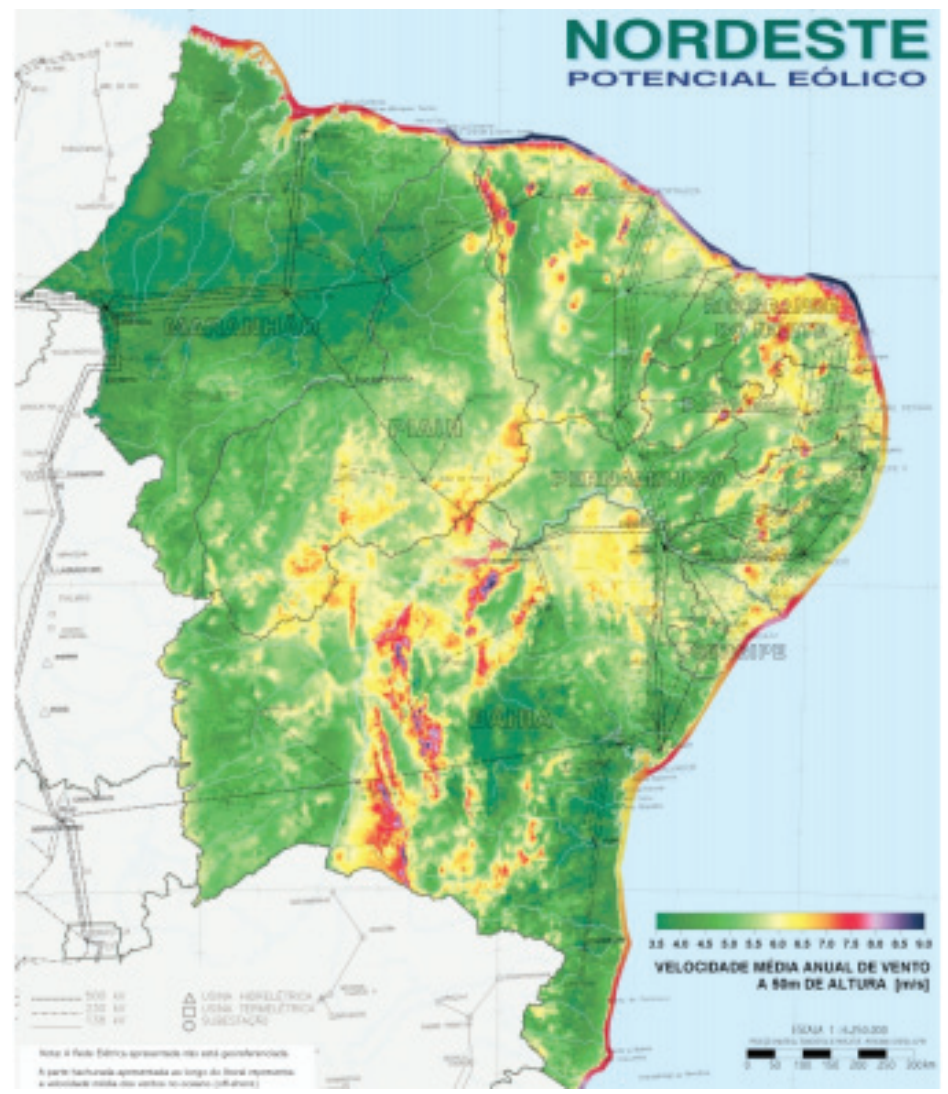

Fonte: Atlas do potencial eólico brasileiro (2001)

\section{Perspectivas para o desenvolvimento do setor eólico no Nordeste}

O uso da energia eólica no mundo vem apresentando expansão nos últimos anos devido à necessidade de os países garantirem a oferta de energia e utilizarem fontes renováveis de energia. A consolidação dos investimentos nos últimos anos vem desenvolvendo o setor eólico numa perspectiva da produção e, também, do complexo industrial eólico. A implementação de incentivos criou um ambiente institucional favorável à atração de investimentos, que vem alavancando o mercado industrial para produção em larga escala (OLIVEIRA NETO, 2012). 
Dados do Conselho Global de Energia Eólica (GWEC) mostram que a energia eólica está em plena expansão. Nos últimos 20 anos a produção de energia por esta fonte vem apresentando grandes resultados, conforme o gráfico 1 a seguir. Percebe-se um aumento constante e quase exponencial na produção de energia por aerogeradores, de forma que, em 2015, a produção bateu um recorde de 432.419 MW (GWEC, 2014).

\section{Gráfico 1- Evolução da Capacidade Instalada de Energia Eólica} Mundial em MW (1996-2014)

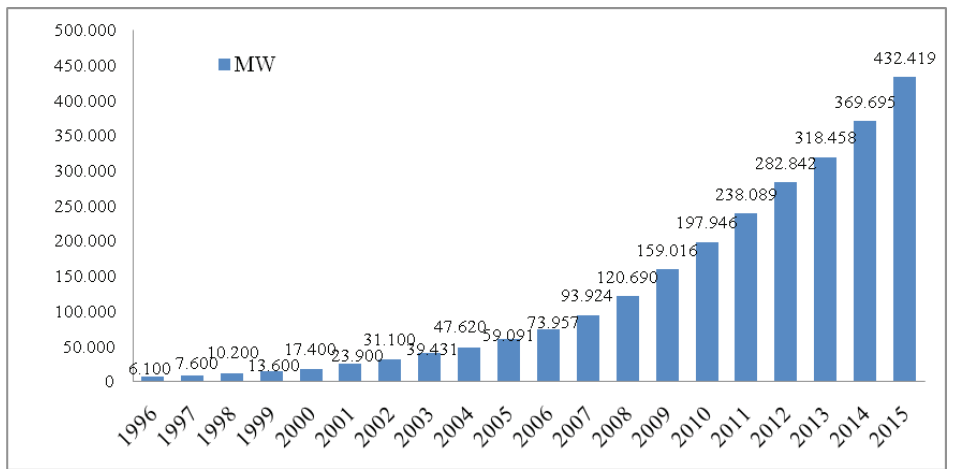

Fonte: Elaboração própria a partir dos dados da GWEC (2014).

Essa expansão extensiva e intensiva da energia eólica possibilitou que, desde a década de 1980, a comercialização de turbinas eólicas também se desenvolvesse rapidamente. Quanto ao impacto na indústria eólica, observa-se que esta produzia aerogeradores com $50 \mathrm{Kw}$ de potência, porém, com o investimento em pesquisa e desenvolvimento tecnológico (P\&D), hoje em dia, é possível produzir turbinas eólicas com capacidade de geração de $7 \mathrm{MW}$ (CRESESB, 2008). Essa expansão é sustentada por investimentos, principalmente de países desenvolvidos, que buscam garantir o suprimento de energia e diminuir a dependência de combustíveis fósseis. Assim, ao desenvolver a energia eólica, esses países a tornam em uma nova atividade econômica, possibilitando a criação de uma indústria altamente tecnológica em regiões com potencial de produção, de modo a tornar-se uma indústria motriz da 
cadeia produtiva dos aerogeradores. Esse é o caso da indústria eólica dinamarquesa, que é caracterizada por constantes inovações tecnológicas, diferenciação e confiabilidade dos seus produtos, eficiência e vantagens absolutas de custos. Isso resulta em garantias de mercado não só internas como também externas, através de exportações de equipamentos e de consultoria (DWIA, 2010).

O Brasil começou a promover a energia eólica a partir da crise de abastecimento de eletricidade ocorrida em 2001. $\mathrm{O}$ racionamento de energia, naquele ano, revelou um grave problema estrutural: a demanda por eletricidade crescia a uma taxa maior que a oferta. Logo, houve a necessidade de se repensar o planejamento elétrico nacional, de forma que o Estado precisava recuperar seu papel de indutor do Sistema Elétrico Brasileiro, agregando sua capacidade de financiamento e de investimento, além de trabalhar em conjunto com o setor privado em parcerias estratégicas (OLIVEIRA NETO, 2012). Por isso, em 2002, foi implantado o Programa de Incentivo as Fontes Alternativas de Energia Elétrica (PROINFA), que colocava em marcha as políticas públicas destinadas à diversificação da matriz elétrica brasileira a partir da introdução de novas fontes alternativas de energia. Assim, abria-se caminho para a atração da indústria eólica com seus componentes e turbinas no país.

As políticas de incentivo a partir do PROINFA foram fundamentais para o processo de aprendizado brasileiro sobre o setor, além do avanço no desenvolvimento tecnológico. As diretrizes do PROINFA garantiam a compra da energia a partir da fonte eólica, além de outras. Assim, tal programa de incentivo gerava um efeito positivo no preço do kilowatt hora $(\mathrm{kW} / \mathrm{h})$ de energia, pois a atração de fabricantes para o mercado estimulava a concorrência, ocasionando uma queda nos preços do $\mathrm{kW} / \mathrm{h}$. Outra medida importante foi a introdução da competição, via leilões públicos, de energia nova, sendo o vencedor aquele que oferecesse a menor tarifa ao consumidor. Por outro lado, como a atividade eólica estava no início, o custo da energia se tornou mais alto pela falta 
de insfraestrutura adequada aos projetos de parques eólicos (GAVINO, 2011; OLIVEIRA NETO, 2016).

De todo modo, o país tem avançado na implementação da cadeia produtiva da atividade eólica no seu território, acumulando conhecimento na montagem dos aerogeradores, na fabricação das torres (de concreto ou de aço) e nos processos de fabricação de bens para os parques. No caso do Nordeste, as políticas de incentivo em conjunto com o seu enorme potencial, permitiram que a região fosse pioneira na instalação de parques eólicos. Assim, é natural que grandes investimentos nacionais e estrangeiros, tanto para a produção de energia quanto para o desenvolvimento do setor industrial, instalem-se na região. Isso vislumbra oportunidades de geração de polos industriais com novos conhecimentos científicos e tecnológicos para a região, investimentos imprescindíveis para mudar sua estrutura tecnológica deficitária. Portanto, os complexos industriais que estão se instalando na região podem contribuir para tornar mais diversificada a sua estrutura produtiva, uma vez que a atividade e seus serviços ainda estão no início. Logo, não há, no momento, como prever o desenvolvimento em longo prazo da energia eólica (OLIVEIRA NETO, 2016).

Em termos de produção de energia, os parques eólicos apresentam uma produção relativamente pequena. Por outro lado, quando se observa a produção de energia, ao longo dos anos, a energia eólica apresenta um crescimento virtuoso:no final de 2015, o Brasil alcançou uma capacidade instalada de 8.71 GW distribuídos em 349 parques eólicos, o que corresponde a $6.2 \%$ da demanda nacional de eletricidade, representando um crescimento de $46 \%$ de potência em relação ao ano de 2014. Esses resultados já colocam o Brasil na décima posição no ranking mundial na produção de energia por fonte eólica (ABEEólica, 2015; GWEC, 2015).

Conforme o Gráfico 2 a seguir, do ano de 2006 a 2015, houve uma grande expansão na produção de energia elétrica por fonte eólica no país. Esse fenômeno foi acelerado com a entrada de indústrias na região, que causam duas consequências práticas, a expansão da oferta e o barateamento dos custos de produção. Quando se analisa os dados por região, o Nordeste 
concentra quase $80 \%$ dos parques eólicos instalados no país dos 8.715 MW do total nacional, 6.888 MW de capacidade instalada estão na região (ABEEólica, 2015) -. Isso é reflexo do seu potencial.

\section{Gráfico 2 - Evolução da capacidade instalada de energia eólica} Brasil

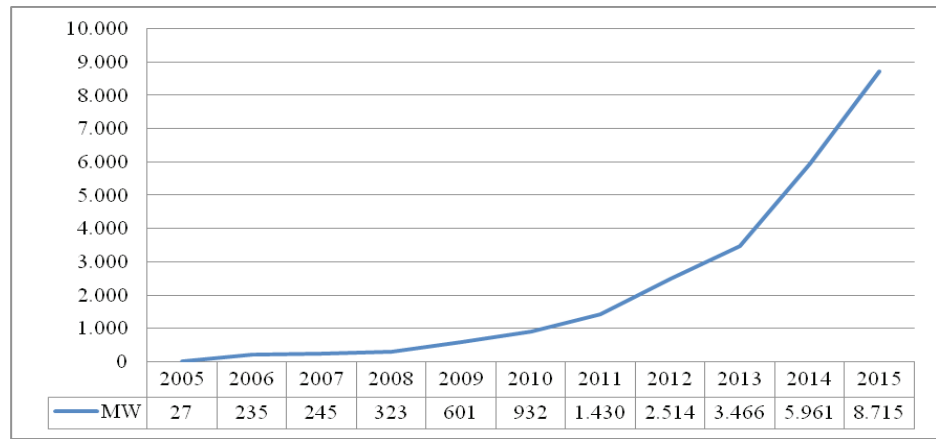

Fonte: ABEEólica (2015)

Essa produção de energia eólica por aerogeradores é suficiente para fornecer eletricidade a 15 milhões de casas. Somente em 2015, foram 111 novos parques eólicos que entraram em operação e 41 mil empregados admitidos na cadeia produtiva do setor. Em termos ambientais, a energia eólica contribuiu em 16 milhões de toneladas para a redução de gases poluentes. Isso demonstra os importantes benefícios econômicos, sociais e ambientais que a energia eólica proporciona (GWEC, 2015).

A indústria eólica e sua cadeia de suprimentos estão se estabelecendo cada vez mais no Brasil. Já são nove fabricantes internacionais que se instalaram no país com objetivo de atender ao Plano Decenal de Energia do governo brasileiro (PDE 2022), que estabelece uma meta de $17 \mathrm{GW}$ de capacidade eólica instalada a ser atingido até 2022 , respondendo por 9,5\% do consumo nacional de energia elétrica. Em 2015, novas fábricas foram inauguradas, abrangendo toda a toda a cadeia de suprimentos da indústria eólica: a empresa SKF entrou no mercado com uma fábrica em Cajamar, em São Paulo, produzindo rolamentos, vedações e sistemas de lubrificação; 
a Gamesa inaugurou sua primeira fábrica de naceles em Camaçari, na Bahia; a Acciona ampliou sua linha de produção no município de Simões Filho, também na Bahia; e, por fim, a TEN-Wind Towers ampliou sua capacidade de produção de 200 torres de aço anualmente no Nordeste (GWEC, 2014, 2015).

Verifica-se, assim, que há uma implantação da indústria eólica e de toda sua cadeia de serviços e de fornecimentos, que a cada ano apresenta uma capacidade produtiva diversificada. $\mathrm{Na}$ Tabela 1 a seguir, é apresentada a cadeia de fornecimento de equipamentos para atender o mercado eólico no Brasil.

Tabela 1 - Fornecimento de equipamentos por estados

\begin{tabular}{|c|c|c|}
\hline Estado & Equipamentos & Fabricante \\
\hline Ceará & $\begin{array}{l}\text { Fábrica de pás de rotores e } \\
\text { fábrica de torres }\end{array}$ & Wobben \\
\hline Pernambuco & $\begin{array}{l}\text { Fábrica de montagem de } \\
\text { turbinas e fábrica de torres }\end{array}$ & Impsa \\
\hline Bahia & $\begin{array}{c}\text { Fábrica de montagem } \\
\text { de turbinas e fábrica de } \\
\text { pás de rotores (ambas em } \\
\text { construção) }\end{array}$ & Gamesa; Suzlon \\
\hline São Paulo & $\begin{array}{l}\text { Fábrica de montagem de } \\
\text { turbinas e fábrica de pás de } \\
\text { rotores }\end{array}$ & Wobben; Tecsis \\
\hline Paraná & Fábrica de torres & Brasilsat \\
\hline Rio Grande do Sul & Fábrica de torres & Intecnial \\
\hline
\end{tabular}

Fonte: Elaborado a partir dos dados da GWEC (2011).

A tabela mostra o domínio das empresas estrangeiras no mercado eólico nacional. Depois de terem desenvolvido os mercados nos seus países de origem, esses fabricantes agora investem estrategicamente para além de suas fronteiras para ganhar mercado em outros países, pois apresentam maturação e domínio da tecnologia. Segundo a GWEC (2011), fabricantes como a General Electric, Alstom, Vestas, Siemens, Suzlon e o fabricante Chinês Guodian-United Power anunciaram investimentos no Brasil, em resposta aos excelentes resultados obtidos nos últimos anos. 
A indústria de aerogeradores está organizada sob a forma de oligopólio com os 4 maiores fabricantes (Vestas, GE Wind, Gamesa e Enercon) possuindo um market share de aproximadamente 70\%. Essas empresas possuem poder de mercado devido à existência de barreiras às entradas referentes à escala de produção e ao caráter de constantes inovações tecnológicas da indústria, que resultam em vantagens absolutas de custo e de diferenciação de produto das firmas estabelecidas (OLIVEIRA NETO, 2012).

Dessa forma, é fundamental que haja incentivos à concorrência, mas, sobretudo, o Estado tem que intervir naquilo que é de interesse nacional. Para tanto, este deve criar incentivos para um padrão estratégico de política industrial, comercial e tecnológica (ICT), levando desenvolvimento econômico para regiões como o Nordeste, que tem baixo desenvolvimento econômico e social. Os investimentos têm que exercer duplo papel na economia: representar um importante componente da demanda agregada e aumentar a capacidade produtiva da economia em longo prazo. Portanto, a participação do Estado como planejador do sistema elétrico e do desenvolvimento regional é fundamental para o aumento da inserção de novas atividades em regiões incipientes econômico e socialmente. Nesse sentido, a continuidade de uma complexa rede de subsídios, programas e políticas precisa ser desenvolvida para o benefício da sociedade como um todo.

\section{Considerações finais}

O presente trabalho teve como objetivo analisar a atividade eólica no Brasil como oportunidade ao desenvolvimento regional e à complementação da matriz elétrica nacional. Nos últimos anos, a discussão sobre a questão do desenvolvimento regional e sobre suas implicações vem sendo ressaltada em muitos estudos. Ao analisar o desenvolvimento brasileiro, observou-se que uma das grandes preocupações diz respeito às disparidades existentes entre as regiões. É necessário que as novas oportunidades de fomento 
ao desenvolvimento regional, como é o caso da atividade eólica, sejam aproveitadas para a implantação de um polo industrial, o que beneficiaria outras atividades no complexo produtivo, pois a atividade eólica é caracterizada pelo processo de constante inovação, pela alta tecnologia e pela $\mathrm{P} \& \mathrm{D}$, que, por sua vez, necessita de proteção por um aparato institucional bem organizado. Contudo, é necessário realizar uma análise mais detalhada do ambiente locacional da energia eólica para postular a formação de um complexo industrial da atividade eólica no Nordeste. Torna-se, portanto, essencial tomar medidas com políticas claras para o setor de energia no Brasil e adotar estratégias para a inserção do Nordeste no complexo industrial de peças e de equipamentos. É necessário diversificar a produção industrial, aproveitando as potencialidades internas à região para fomentar o crescimento e o desenvolvimento econômico regional.

Os benefícios da implantação da energia eólica para a segurança energética do mundo, inclusive para o Brasil, são indiscutíveis. A participação do Estado como planejador do sistema elétrico é a maneira mais adequada e eficiente para o aumento da inserção da energia eólica na matriz elétrica. $\mathrm{O}$ ambiente institucional precisa ser melhorado para atrair mais investimentos para o setor. Com as políticas públicas já implementadas, os investimentos de empresas estrangeiras vêm aumentando e a instalação desse complexo industrial, principalmente no Nordeste, pode criar incentivos para um padrão estratégico de política industrial,comercial e tecnológico (ICT). Sendo assim, uma complexa rede de subsídios, programas e políticas públicas precisa ser desenvolvida para a geração de benefícios sociais, econômicos e ambientais. Por outro lado, o país possui gargalos estruturais que também necessitam de intervenção, como estradas precárias para a implantação dos projetos, novas linhas de transmissão, orientação técnica para os proprietários de terrenos com potencial de geração, etc. Logo, parcerias estratégicas entre o setor público e o privado podem ser idealizadas para o benefício da sociedade como um todo. 


\section{Referências}

ABEEÓlICA: ASSOCIAÇÃO BRASILEIRA DE ENERGIA EÓLICA. Boletim anual de geração, 2015. Disponível em: http:// www.abeeolica.org.br/wpcontent/uploads/2016/08/Abeeolica_ BOLETIM-2015_low.pdf. Acesso em: 28 jan. 2016.

. Boletim de Dados de Janeiro de 2016. 2016. Disponível em: <http://abeeolica.org.br/pdf/Boletim-de-Dados-ABEEolicaJaneiro-2016-Publico.pdf>. Acesso em: 15 set. 2016.

ATLAS DO POTENCIAL EÓLICA BRASILEIRO, 2001. Disponível em: http://www.cresesb.cepel.br/publicacoes/download/ atlas_eolico/Atlas\%20do\%20Potencial\%20Eolico\%20Brasileiro. pdf. Acesso em: 28 jan. 2016.

BENKO, G. A ciência regional. Oeiras: Celta, 1999.

CANO, W. Desconcentração produtiva regional do Brasil: 19702005. São Paulo: UNESP, 2008.

CASTRO, N. J. et. al. Considerações sobre as perspectivas da matriz elétrica brasileira.. Textos de Discussão do Setor Elétrico, Rio de Janeiro, n. 19, 2010. Disponível em: <http://www.gesel.ie.ufrj.br/ app/webroot/files/publications/44_TDSE19.pdf >. Acesso em: 18 set. 2016.

CLEMENTE, A. Economia regional e urbana. São Paulo: Atlas S.A, 1994.

CRESESB - CENTRO DE PESQUISA DE ENERGIA ELÉTRICA (Org.). Potencial eólico do Brasil. 2001. Disponível em: <http://www.cresesb.cepel.br/index.php?link=/atlas_eolico_ brasil/atlas.htm>. Acesso em: 20 mar. 2016.

CRESESB - Centro de Referência para Energia Solar e Eólica Sérgio de Salvo Brito. Energia eólica: princípios e tecnologias. Organização de: Ricardo Dutra. 2008. Disponível em: < http://www. cresesb.cepel.br/download/tutorial/tutorial_eolica_2008_e-book. pdf>. Acesso em: 16 set. 2016.

Danish Wind Industry Association - DWIA. Annual Statistics. 2010. Disponível em: <http://www.windpower.org/en/knowledge/ statistics.html>. Acesso em: 18 set. 2016.

DUTRA, R. M. Viabilidade Técnico-Econômica da Energia Eólica Face ao Novo Marco Regulatório do Setor Elétrico 
Brasileiro. 2001. 309 p. Dissertação (mestrado em Planejamento Energético). Universidade Federal do Rio de Janeiro, COPPE, Rio de Janeiro, 2001.

FURTADO, C. Subdesenvolvimento e estagnação na América Latina. Rio de Janeiro: Civilização Brasileira, 1966.

FURTADO, C. A. Introdução ao desenvolvimento: enfoque histórico-estrutural. 3. ed. Rio de Janeiro: Paz e Terra, 2000.

O subdesenvolvimento revisitado. Economia e Sociedade, Campinas, SP, n. 1, p. 5-19, 1992.

GAVINO, N. A. Energia eólica: uma análise dos incentivos à produção (2002-2009). Rio de Janeiro: Instituto de Economia da Universidade Federal do Rio de Janeiro, 2011.

Global Wind Energy Council - GWEC. Global Wind Report: Analysis of the regulatory framework for wind power generation in Brazil. 2011. Disponível em: http://gwec.net/wp-content/ uploads/2012/06/Brazil_report_2011.pdf. Acesso em: 15 nov. 2016.

2014. . Global Wind Report: Annual Market Update. uploads/2015/03/GWEC_Global_Wind_2014_Report_LR.pdf >. Acesso em: 17 nov. 2016.

. Global Wind Report: Annual Market Update. 2015. Disponível em: http://www.gwec.net/wp-content/uploads/vip/ GWEC-Global-Wind-2015-Report_April-2016_22_04.pdf. Acesso em: 20 nov. 2016.

GOLDEMBERG, J. Energia e desenvolvimento sustentável. São Paulo: Blucher, 2010. Série Sustentabilidade.

HADDAD, P. R.; ANDRADE, T. A.; Métodos de análise regional. In: HADDAD, P. R. (Org.). Economia regional: teorias e métodos de análise. Fortaleza: Banco do Nordeste do Brasil - ETENE, 1989.

INTERNATIONAL ENERGY AGENCY - IEA. World Energy Outlook. Paris: [s.n.], 2015.

LIMA, E. C. Análise do emprego formal no setor industrial do Rio Grande do Norte: uma abordagem espacial para os anos 2002 e 2012. 2015. 80 f. Dissertação (Mestrado em economia)Universidade Federal do Rio Grande do Norte, Natal, 2015.

OLIVEIRA NETO, C. R. Energia eólica e desenvolvimento no terceiro milênio: reflexões a partir do Brasil, Nordeste e Rio Grande do Norte. 2016. 159 f. Dissertação (Mestrado em Economia) Universidade Federal do Rio Grande do Norte, Natal, 2016. 
OLIVEIRA NETO. C. R. Energia eólica no Brasil: mais do que uma alternativa energética. 2012.116 f. Monografia (Graduação em Economia)-Universidade Federal do Rio Grande do Norte. Natal, 2012.

OLIVEIRA, F. A. Política econômica, estagnação e crise mundial: Brasil, 1980-2010. Rio de Janeiro: Beco do Azougue, 2012.

OTTAVIANO, G. I. P; THISSE J. F. New economic geography: what about the N?. Environment and Planning A, v. 37, n. 10, p. 1707-1725, 2004.

PACHECO, C. A. A. A questão regional brasileira pós 1980: desconcentração econômica e fragmentação da economia nacional. 1998.334 f. Tese (Doutorado em Economia)-Instituto de Economia, Universidade Estadual de Campinas, Campinas, SP, 1997.

SACHS, I. A revolução energética do século XX. Estudos Avançados, São Paulo, v. 21, n. 59, p. 21-38, 2007.

SOUZA, N. J. Economia regional: conceito e fundamentos teóricos. Perspectiva Econômica, São Leopoldo, ano 16, v. 11, n. 32, p. 67102, 1981. Disponível em: <http://www.nalijsouza.web.br.com/ downloads/outros-textos/desenvolvimento/teoria_econ_reg.pdf $>$. Acesso em: 15 set. 2016.

Submetido em: 02/09/2016

Aceito em: 23/11/2016

\title{
NEW DEVELOPMENT PERSPECTIVES:
} AN ANALYSIS OF WIND POWER IN BRASIL

\begin{abstract}
This article aims to analyze a consolidation of wind activity in Brazil and its perspective of regional development. In methodological terms, a research was developed through a bibliographical and documentary review, as well as the descriptive analysis of data collected in public and private institutions related to the sector. The results show that programs to encourage the growth of wind energy have leveraged investments, providing greater knowledge and competitiveness. This panorama benefits from regional, social and environmental development, as well as diversifying a national energy matrix. Thus, with the State promoting incentive policies, for an attraction of investment and foreigners in the country, it expands production and, consequently, a formation of an industrial pole, mainly in the Northeast region, due to its greater potential in wind resources.
\end{abstract}

Keywords: Regional Development. Wind Energy. Northeast. 